\title{
Cochrane
}

Library

Cochrane Database of Systematic Reviews

\section{Biphasic versus monophasic oral contraceptives for contraception} (Review)

Van Vliet HAAM, Grimes DA, Helmerhorst FM, Schulz KF, Lopez LM

Van Vliet HAAM, Grimes DA, Helmerhorst FM, Schulz KF, Lopez LM.

Biphasic versus monophasic oral contraceptives for contraception.

Cochrane Database of Systematic Reviews 2006, Issue 3. Art. No.: CD002032.

DOI: 10.1002/14651858.CD002032.pub2.

www.cochranelibrary.com 
TABLE OF CONTENTS

HEADER 1

ABSTRACT

PLAIN LANGUAGE SUMMARY

BACKGROUND

OBJECTIVES

METHODS

RESULTS

DISCUSSION

AUTHORS' CONCLUSIONS

ACKNOWLEDGEMENTS

REFERENCES

CHARACTERISTICS OF STUDIES

DATA AND ANALYSES

Analysis 1.1. Comparison 1 Biphasic norethindrone/ethinyl estradiol versus monophasic norethindrone acetate/ethinyl estradiol, Outcome 1 Intermenstrual bleeding.

Analysis 1.2. Comparison 1 Biphasic norethindrone/ethinyl estradiol versus monophasic norethindrone acetate/ethinyl estradiol, Outcome 2 Absence of withdrawal bleeding.

Analysis 1.3. Comparison 1 Biphasic norethindrone/ethinyl estradiol versus monophasic norethindrone acetate/ethinyl estradiol, Outcome 3 Study discontinuation due to intermenstrual bleeding.

APPENDICES

WHAT'S NEW

HISTORY

CONTRIBUTIONS OF AUTHORS

DECLARATIONS OF INTEREST

SOURCES OF SUPPORT

INDEX TERMS 
[Intervention Review]

\section{Biphasic versus monophasic oral contraceptives for contraception}

Huib AAM Van Vliet ${ }^{1}$, David A Grimes ${ }^{2}$, Frans M Helmerhorst ${ }^{3}$, Kenneth F Schulz ${ }^{4}$, Laureen M Lopez ${ }^{2}$

1Department of Gynaecology, Division of Reproductive Medicine, Leiden University Medical Center, Leiden, Netherlands. ${ }^{2}$ Clinical Sciences, FHI, Research Triangle Park, North Carolina, USA. ${ }^{3}$ Gynaecology, Division of Reproductive Medicine and Dept. of Clinical Epidemiology, Leiden University Medical Center, Leiden, Netherlands. ${ }^{4}$ Quantitative Sciences, FHI, Research Triangle Park, North Carolina, USA

Contact address: David A Grimes, Clinical Sciences, FHI, PO Box 13950, Research Triangle Park, North Carolina, NC 27709, USA. dgrimes@fhi.org.

Editorial group: Cochrane Fertility Regulation Group.

Publication status and date: New search for studies and content updated (no change to conclusions), published in Issue 6, 2011.

Citation: Van Vliet HAAM, Grimes DA, Helmerhorst FM, Schulz KF, Lopez LM. Biphasic versus monophasic oral contraceptives for contraception. Cochrane Database of Systematic Reviews 2006, Issue 3. Art. No.: CD002032. DOI: 10.1002/14651858.CD002032.pub2.

Copyright ( 2011 The Cochrane Collaboration. Published by John Wiley \& Sons, Ltd.

\section{A B S T R A C T}

\section{Background}

Side effects caused by oral contraceptives discourage compliance with, and continuation of, oral contraceptives (OCs). Three approaches have been used to decrease these adverse effects: reduction of steroid dose, development of new steroids, and new formulas and schedules of administration. The third strategy led to the biphasic oral contraceptive pill.

\section{Objectives}

To compare biphasic with monophasic oral contraceptives in terms of efficacy, cycle control, and discontinuation due to side effects. Our a priori hypotheses were: (a) biphasic oral contraceptives are less effective than monophasic OCs in preventing pregnancy; (b) biphasic oral contraceptives cause more side effects, give poorer cycle control, and have lower continuation rates.

\section{Search methods}

We searched the computerized databases MEDLINE, POPLINE, LILACS and CENTRAL, as well as clinical trials databases (ClinicalTrials.gov and ICTRP). In addition, we searched the reference lists of relevant articles and book chapters. We also contacted the authors of relevant studies and pharmaceutical companies.

\section{Selection criteria}

We included randomized controlled trials comparing any biphasic with any monophasic $\mathrm{OC}$ when used to prevent pregnancy.

\section{Data collection and analysis}

We examined the studies found during the various literature searches for possible inclusion and assessed their methodology using Cochrane guidelines. We contacted the authors of included studies and possibly randomized studies for information about methodology and outcomes. We entered the data into RevMan, and calculated Peto odds ratios for the incidence of intermenstrual bleeding, absence of withdrawal bleeding, and study discontinuation due to intermenstrual bleeding.

\section{Main results}

Only one trial of limited quality compared a biphasic and monophasic preparation. The study examined 533 user cycles of a biphasic pill (500 $\mu \mathrm{g}$ norethindrone plus $35 \mu \mathrm{g}$ ethinyl estradiol (EE) for 10 days, followed by $1000 \mu \mathrm{g}$ norethindrone plus $35 \mu \mathrm{g}$ EE for 11 days; Ortho $10 / 11$ ) and 481 user cycles of a monophasic contraceptive pill (1500 $\mu \mathrm{g}$ norethindrone acetate plus $30 \mu \mathrm{g}$ EE daily; Loestrin). The study found no significant differences in intermenstrual bleeding, amenorrhea and study discontinuation due to intermenstrual bleeding between the biphasic and monophasic oral contraceptive pills. 


\section{Authors' conclusions}

Conclusions are limited by the identification of only one trial, the methodological shortcomings of that trial, and the absence of data on accidental pregnancies. However, the trial found no important differences in bleeding patterns between the biphasic and monophasic preparations studied. Since no clear rationale exists for biphasic pills and since extensive evidence is available for monophasic pills, the latter are preferred.

\section{PLAIN LANGUAGE SUMMARY}

\section{Birth control pills with two phases versus one phase}

Side effects of birth control pills may keep women from using them as planned. Attempts to decrease side effects led to the two-phase pill. Pills with phases provide different amounts of hormones over three weeks. Whether two-phase pills lead to fewer pregnancies than onephase pills is unknown. Nor is it known if the pills give better cycle control or have fewer side effects. This review looked at whether twophase pills worked as well as one-phase pills. It also studied whether women had fewer side effects with these pills.

We did a computer search for studies of birth control pills with two phases versus pills with one phase. We also wrote to researchers and manufacturers to find other trials. We included randomized trials in any language.

We found only one trial that looked at one-phase versus two-phase birth control pills. The study authors did not report all their methods. Many of the women dropped out of the trial, and the authors did not give the reasons. The pills did not differ in any major ways, including bleeding patterns and the numbers of women who stopped using the pills.

This review did not find enough evidence to say if two-phase pills worked any better than one-phase types for birth control, bleeding patterns, or staying on the pill. The one trial report had method problems and lacked data on pregnancies. Therefore, one-phase pills are the better choice, since we have much more evidence for such pills and two-phase pills have no clear reason for use. 


\section{B A C K G R O U N D}

Side effects caused by oral contraceptives discourage compliance with and continuation of oral contraceptives (Hillard 1992). Three approaches have been used to decrease these adverse effects: reduction of the steroid dose, development of new steroids, and new formulas and schedules of administration. The third strategy led to the biphasic oral contraceptive pill.

Biphasic oral contraceptives purportedly attempt to 'mimic' the rising and falling pattern of estrogen and progesterone as seen during the normal menstrual cycle (Upton 1983). Overall, this results in a lower total monthly steroid dosage in comparison with most older monophasic oral contraceptives. However, alleged disadvantages of the biphasic approach are a decline in cycle control and a higher incidence of pregnancy. Several observational studies have suggested that multiphasic pills may be associated with higher pregnancy rates compared with monophasic pills (Ketting 1988; Kovacs 1989). We conducted this systematic review to examine these potential differences.

\section{O B JE C T IVES}

The aim of this review was to compare biphasic with monophasic oral contraceptive pills. Our a priori hypotheses were: (a) biphasic oral contraceptives are less effective than monophasic oral contraceptives in preventing pregnancy (Ketting 1988; Kovacs 1989); (b) biphasic oral contraceptives cause more side effects, give poorer cycle control, and have lower continuation rates.

\section{METHODS}

\section{Criteria for considering studies for this review \\ Types of studies}

We included only randomized controlled trials in this review.

\section{Types of participants}

Healthy women of reproductive age without contra-indications for the use of oral contraceptive who wanted oral contraceptives for preventing pregnancy.

\section{Types of interventions}

We included any biphasic compared with any monophasic oral contraceptive pill when used to prevent pregnancy. Both 21-pill and 28-pill packages are included. We excluded studies that examined sequential pills (those containing estrogen alone early in the cycle, followed by estrogen plus progestin later in the cycle). We also excluded studies that compared biphasic with monophasic pills when the pills were used as a treatment and not as a contraceptive.

\section{Types of outcome measures}

\section{Primary outcomes}

Principal outcome measures included the incidence of accidental pregnancy, spotting, breakthrough bleeding, intermenstrual bleeding, amenorrhea, and discontinuation due to side effects.

We excluded studies that focused primarily on metabolic outcome measures and follicular growth and which did not provide data of clinical interest.

\section{Search methods for identification of studies}

\section{Electronic searches}

We searched computerized databases MEDLINE using PubMed, POPLINE, LILACS and Cochrane Central Register of Controlled Trials (CENTRAL) for publications comparing monophasic, biphasic or triphasic oral contraceptives. In addition, we searched for recent clinical trials through ClinicalTrials.gov and the International Clinical Trials Registry Platform (ICTRP). The current search strategies are shown below, along with the search dates. For the initial review (2006) and the 2008 update, we also searched EMBASE (Appendix 1).

\section{MEDLINE via PubMed (Jun 2008 to 02 May 2011)}

contraceptives, oral[MeSH Terms] AND (monophasic[ALL] OR biphasic[ALL] OR triphasic[ALL] OR multiphasic[ALL]) AND (clinical trials[MeSH Terms] OR clinical trial*[ALL] OR controlled clinical trial ${ }^{*}[\mathrm{ALL}]$ OR comparative stud ${ }^{*}[\mathrm{ALL}] \mathrm{OR}$ compar ${ }^{\star}$ OR randomized controlled trial[ALL] OR random allocation[MeSH Terms] OR random allocation[Text Word] OR random[ALL] OR double-blind method[MeSH Terms] OR double blind method[Text Word] OR single-blind method[MeSH Terms] OR single blind method[Text Word] OR multicenter stud $\left.{ }^{*}[A L L]\right)$

\section{POPLINE (past 5 years to 03 May 2011)}

(oral \& contracept ${ }^{\star}$ ) \& (monophasic/biphasic/triphasic/ multiphasic)

\section{LILACS (to 03 May 2011)}

(((("contraceptives, oral") or "contraceptive")) or "contraceptives") or "contraception" [Words]

and

((("monophasic") or "biphasic") or "triphasic") or

"multiphasic" [Words]

\section{CENTRAL (2008 to 02 May 2011)}

oral AND contracept ${ }^{\star}$ in Title, Abstract or Keywords AND (monophasic OR biphasic OR triphasic OR multiphasic) in Abstract

\section{ClinicalTrials.gov (03 May 2011)}

Search terms: biphasic OR triphasic OR multiphasic Condition: NOT diabetes Interventional Studies

Studies with Female Participants

Received on or after $07 / 01 / 2008$

\section{ICTRP (03 May 2011)}

Intervention: (monophasic OR biphasic OR triphasic OR multiphasic) NOT insulin

Date of registration from $01 \mathrm{Jul} 2008$

\section{Searching other resources}

For the initial review, we searched relevant book chapters and review articles identified with the above searches for relevant trials. We reviewed the reference lists of identified studies for previously unidentified trials. We also searched the holdings of the FHI Library for relevant trials, book chapters and review articles. 
We attempted to contact the authors of all included trials. For the initial review, we also wrote letters to pharmaceutical companies in the USA and Europe that market oral contraceptives. We did not contact the US Food and Drug Administration. In the contact letters, we provided a list of studies that had been identified and asked if correspondents knew of unpublished or published trials that we had not found.

\section{Data collection and analysis}

\section{Selection of studies}

For the initial review, two authors evaluated the titles and abstracts found during the literature search, and all potentially relevant articles were photocopied. Two authors independently examined each study for possible inclusion. For the updates, one author reviewed the search results and identified reports for inclusion or exclusion. A second author examined reports identified for appropriate categorization.

\section{Data extraction and management}

After inclusion of the study, two authors abstracted the data. There was no disagreement about the inclusion of studies or the abstracted data. We wrote to the author of the one study included and to the author of a possibly randomized study. In the letters we asked for details about the methods used in the study and the various outcome measures. We then entered the data into RevMan 3.1, and later imported the review into RevMan 4.1. Another author verified that the data had been correctly entered.

\section{Assessment of risk of bias in included studies}

We assessed the methodology using Cochrane guidelines. We focused on the method of randomization, use of allocation concealment, use of blinding, and exclusion of participants after randomization.

\section{Data synthesis}

We calculated Peto odds ratios (Peto OR) with 95\% confidence intervals $(\mathrm{Cl})$ for the incidence of intermenstrual bleeding, amenorrhea, and study discontinuation due to intermenstrual bleeding. Since person-time denominators do not allow calculation of true odds ratios, the odds ratios (OR) reported in RevMan should be considered as approximations. Cycles of exposure were the denominators for bleeding outcomes, and a woman could experience an outcome in more than one cycle.

\section{RES U L T S}

\section{Description of studies}

\section{Included studies}

Only one study (Percival-Smith 1990) met the inclusion criteria for this review. The trial compared a monophasic pill containing $1500 \mu \mathrm{g}$ norethindrone acetate plus $30 \mu \mathrm{g}$ ethinyl estradiol daily (Loestrin, Parke-Davis) with three different multiphasic pills. These included one biphasic oral contraceptive pill (Ortho 10/11, Ortho Pharmaceuticals) and two triphasic pills (Triphasil, Wyeth-Ayerst; Ortho $7 / 7 / 7$, Ortho Pharmaceuticals). The biphasic formulation contained $500 \mu \mathrm{g}$ norethindrone plus $35 \mu \mathrm{g}$ EE daily for 10 days, followed by 11 days of $1000 \mu \mathrm{g}$ norethindrone plus $35 \mu \mathrm{g} E \mathrm{E}$. This review only focuses on the comparison in this study between the biphasic and monophasic pills.
The trial randomized 469 women, of whom only 391 women had begun taking the pills and completed at least one month. A total of 116 women were randomized to receive the biphasic, while 117 women were allocated to the monophasic pill. Of these, 81 women assigned to the biphasic pill completed six cycles of use, in contrast to 68 women assigned to the monophasic pill. The main objective of the trial was to compare bleeding patterns with the different products over a six-month observation period. Women were asked to maintain diary cards for their bleeding.

\section{Excluded studies}

We excluded five studies from this review. Balogh 1988 reported only that the study was prospective but did not mention randomization, and we were unable to reach the author. We excluded two studies (Gaspard 1983; Dik 1984) that examined sequential pills. Because of probable fraud (Rossiter 1992), we excluded two studies by Briggs (Briggs 1980; Briggs 1982).

\section{Risk of bias in included studies}

The included study (Percival-Smith 1990) was a randomized controlled trial with the investigators blinded to treatment. The study was sponsored by Parke-Davis, manufacturer of a monophasic pill. The report neither described the method of randomization nor the use of allocation concealment. It did, however, provide an a priori hypothesis and a sample size calculation. Of the 469 women who started the trial, 169 women discontinued after randomization. The reasons for discontinuation are unclear. This raises the strong possibility of selection bias in this study.

\section{Effects of interventions}

This trial examined 533 user cycles of the biphasic pill and 481 user cycles of the monophasic pill. The term 'Intermenstrual bleeding' included both breakthrough bleeding and spotting ("bleeding during active medication which is limited to minor staining, whether or not sanitary protection was used"). For all user cycles, the odds ratio of intermenstrual bleeding with the biphasic pill was 1.3 times higher than that with the monophasic pill (Analysis 1.1: OR $1.29 ; 95 \% \mathrm{Cl} 0.99$ to 1.69$)$. The reported rates of intermenstrual bleeding (34\% and $29 \%$, respectively) cannot be confirmed from the data provided. For all user cycles, the odds ratio of failure to have withdrawal bleeding with the biphasic pill was 0.7 times that with the monophasic pill (Analysis 1.2: OR $0.71 ; 95 \% \mathrm{Cl} 0.43$ to 1.18). Again, the published numbers do not confirm the reported incidence rates ( $5 \%$ and $6 \%$, respectively). The frequency of study discontinuation due to intermenstrual bleeding was similar in both groups (Analysis 1.3: OR 0.97; 95\% Cl 0.33 to 2.86).

\section{DISCUSSION}

We identified only one randomized controlled trial comparing a biphasic and monophasic regimen (Percival-Smith 1990). The study enrolled a limited number of participants and had four different treatment arms. Of the women participating in the trial, 36\% discontinued after randomization, and the reasons for discontinuation are unclear. The report described neither the method of randomization nor the use of allocation concealment. Exclusion after randomization as well as inadequate allocation concealment can bias results (Schulz 1995; Schulz 1996). Unclear denominators in the published report precluded our replication of the reported incidence rates for several outcomes. 
We were unable to confirm or refute our a priori hypotheses about biphasic pills. We postulated that the multiphasic pill could result in higher pregnancy rates, more side effects, and poorer continuation rates than the monophasic pill. Reasons for our inability to reach a conclusion include the identification of only one trial, the methodological shortcomings of that trial, and the absence of data on pregnancies. The trial reported no significant differences between the biphasic and monophasic preparation in intermenstrual bleeding and amenorrhea, and similar proportions of women quit the study because of intermenstrual bleeding.

\section{AUTHORS' CONCLUSIONS}

\section{Implications for practice}

Data are insufficient to compare biphasic and monophasic combined oral contraceptives adequately. This dearth of information probably has little public health impact, since biphasic pills are not as widely available today as monophasic and triphasic pills (Wallach 2000). The putative benefits of the lower total steroid dose per cycle remain to be established. No scientific rationale for biphasic pills exists, and far greater experience is available for monophasic pills. Hence, monophasic are preferred over biphasic pills, although information is limited concerning the latter.

\section{Implications for research}

Given the limited availability and use of biphasic oral contraceptives today, further research on this regimen is of low priority. However, claims of superiority for all new pill regimens should require that randomized controlled trials be properly conducted as supporting evidence.

\section{A CKN OWLEDGEMENTS}

Carol Manion of $\mathrm{FHI}$ assisted with the literature search. 


\section{R E F E R E N C E S}

\section{References to studies included in this review}

Percival-Smith 1990 \{published and unpublished data\}

Percival-Smith RK, Yuzpe AA, Desrosiers JA, Rioux JE, Guilbert E. Cycle control on low-dose oral contraceptives: a comparative trial. Contraception 1990;42:253-62.

\section{References to studies excluded from this review}

\section{Balogh 1988 \{published data only\}}

Balogh A. Clinical and endocrine effects of long-term hormonal contraception. Acta Medica Hungarica 1986;43:97-102.

\section{Briggs 1980 \{published data only\}}

Briggs M, Briggs M. A randomized study of metabolic effects of four oral contraceptive preparations containing levonorgestrel plus ethinylestradiol in different regimens. The development of a new triphasic oral contraceptive. Proceedings of a Special Symposium held at the 10th World Congress on Fertility and Sterility; 1980 July; Madrid. Lancaster (England): MTP Press, 1980:79-88.

\section{Briggs 1982 \{published data only\}}

Briggs $\mathrm{MH}$, Briggs M. Randomized prospective studies on metabolic effects of oral contraceptives. Acta Obstetrica et Gynecologica Scandinavica Supplement 1982;105:25-32.

\section{Dik 1984 \{published data only\}}

Dik M, Eckert H, Hones S, Schindler AE. Comparison of a 2-phase preparation (Oviol 22) with a low-dose 1-phase preparation (Ovoresta M) [Vergleich eines Zweiphasenpraparates (Oviol 22) mit einem niedrig dosierten Einphasenpraparat (Ovoresta M)]. Geburtshilfe Frauenheilkunde 1984;44:808-12.

\section{Gaspard 1983 \{published data only\}}

Gaspard UJ, Romus MA, Gillain D, Duvivier J, Demey-Ponsart E, Franchimont P. Plasma hormone levels in women receiving new oral contraceptives containing ethinyl estradiol plus levonorgestrel or desogestrel. Contraception 1983;27:577-90.

\section{Additional references}

Hillard 1992

Hillard PJA. Oral contraception noncompliance: the extent of the problem. Advances in Contraception 1992;8 Suppl 1:13-20.

\section{Ketting 1988}

Ketting $\mathrm{E}$. The relative reliability of oral contraceptives: findings of an epidemiological study. Contraception 1988;37:343-8.

\section{Kovacs 1989}

Kovacs GT, Riddoch G, Duncombe P, Welberry L, Chick P, Weisberg E, et al. Inadvertent pregnancies in oral contraceptive users. Medical Journal of Australia 1989;150:549-51.

\section{Rossiter 1992}

Rossiter EJR. Reflections of a whistle-blower. Nature 1992;357:434-6.

\section{Schulz 1995}

Schulz KF, Chalmers I, Hayes RJ, Altman DG. Empirical evidence of bias: dimensions of methodological quality associated with estimates of treatment effects in controlled trials. Journal of the American Medical Association 1995;273:408-12.

\section{Schulz 1996}

Schulz KF. Randomised trials, human nature, and reporting guidelines. Lancet 1996;348:596-8.

\section{Upton 1983}

Upton GV. The phasic approach to oral contraception: the triphasic concept and its clinical application. International Journal of Fertility 1983;28:121-40.

\section{Wallach 2000}

Wallach M, Grimes DA, Chaney EJ, Connell EB, Creinin MD, Emans SJ, et al. Modern Oral Contraception. Totowa (NJ): Emron, Inc., 2000.

\section{References to other published versions of this review Van Vliet 2002}

Van Vliet H, Grimes D, Helmerhorst F, Schulz K. Biphasic versus monophasic oral contraceptives for contraception. Human Reproduction 2002;17:870-3.

\section{CHARACTERISTICS OF STUDIES}

Characteristics of included studies [ordered by study ID]

\section{Percival-Smith 1990}

Methods Randomized controlled trial with blinding of the investigators. Adequacy of the blinding is unknown. The method of randomization and the use of allocation concealment were not described.

Participants

469 women, 15 to 35 years, at four Canadian sites. Only 391 women were admitted to the study and used the pills for at least one month. Whether potential participants were not admitted or admitted and lost to follow up is unknown. 
Percival-Smith 1990 (Continued)

Interventions Biphasic (norethindrone $500 \mu \mathrm{g}$ plus EE $35 \mu \mathrm{g}$ daily for 10 days, followed by norethindrone $1000 \mu \mathrm{g}$ plus EE $35 \mu \mathrm{g}$ daily for 11 days; Ortho 10/11; Ortho Pharmaceuticals) or monophasic pill (norethindrone acetate $1500 \mu$ g plus EE $30 \mu \mathrm{g}$ daily; Loestrin; Parke-Davis)

Outcomes Primary outcomes measures were side effects, cycle control, continuation rates, discontinuation rates and reason for discontinuation.

Notes

The report provides an a priori hypothesis and a sample size calculation. 169 women discontinued, and the reasons for discontinuation are unclear. Intermenstrual bleeding includes both breakthrough bleeding and spotting. Use of daily diary method to collect data on cycle control and side effects.

\section{Risk of bias}

\begin{tabular}{lll}
\hline Bias & Authors' judgement & Support for judgement \\
\hline $\begin{array}{l}\text { Allocation concealment } \\
\text { (selection bias) }\end{array}$ & Unclear risk & No information \\
\hline
\end{tabular}

Characteristics of excluded studies [ordered by study ID]

\begin{tabular}{ll}
\hline Study & Reason for exclusion \\
\hline Balogh 1988 & $\begin{array}{l}\text { The report is described only as prospective, and randomization is not mentioned. We attempted } \\
\text { without success to reach the author. }\end{array}$ \\
\hline Briggs 1980 & Briggs is suspected of scientific fraud (Rossiter 1992). Report focuses on metabolic outcomes. \\
\hline Briggs 1982 & $\begin{array}{l}\text { Briggs is suspected of scientific fraud (Rossiter 1992). Report describes } 2 \text { studies. One study com- } \\
\text { pares } 4 \text { monophasic oral contraceptives in terms of metabolic changes. The other is a duplicate } \\
\text { publication (Briggs 1980). }\end{array}$ \\
\hline Dik 1984 & The study examined a sequential pill. \\
\hline Gaspard 1983 & The study examined metabolic outcomes related to a sequential pill. \\
\hline
\end{tabular}

\section{DATA AND ANALYSES}

\section{Comparison 1. Biphasic norethindrone/ethinyl estradiol versus monophasic norethindrone acetate/ethinyl estradiol}

\begin{tabular}{lllll}
\hline Outcome or subgroup title & No. of studies & $\begin{array}{l}\text { No. of partici- } \\
\text { pants }\end{array}$ & Statistical method & Effect size \\
\hline 1 Intermenstrual bleeding & 1 & 1014 & $\begin{array}{l}\text { Peto Odds Ratio (Peto, Fixed, 95\% } \\
\text { Cl) }\end{array}$ & $1.29[0.99,1.69]$ \\
\hline 2 Absence of withdrawal bleeding & 1 & 1014 & $\begin{array}{l}\text { Peto Odds Ratio (Peto, Fixed, 95\% } \\
\text { Cl) }\end{array}$ & $0.71[0.43,1.18]$ \\
\hline
\end{tabular}




\begin{tabular}{lllll}
\hline Outcome or subgroup title & No. of studies & $\begin{array}{l}\text { No. of partici- } \\
\text { pants }\end{array}$ & Statistical method & Effect size \\
\hline $\begin{array}{l}\text { 3 Study discontinuation due to } \\
\text { intermenstrual bleeding }\end{array}$ & 1 & 193 & $\begin{array}{l}\text { Peto Odds Ratio (Peto, Fixed, 95\% } \\
\text { Cl) }\end{array}$ & $0.97[0.33,2.86]$ \\
\hline
\end{tabular}

Analysis 1.1. Comparison 1 Biphasic norethindrone/ethinyl estradiol versus monophasic norethindrone acetate/ethinyl estradiol, Outcome 1 Intermenstrual bleeding.

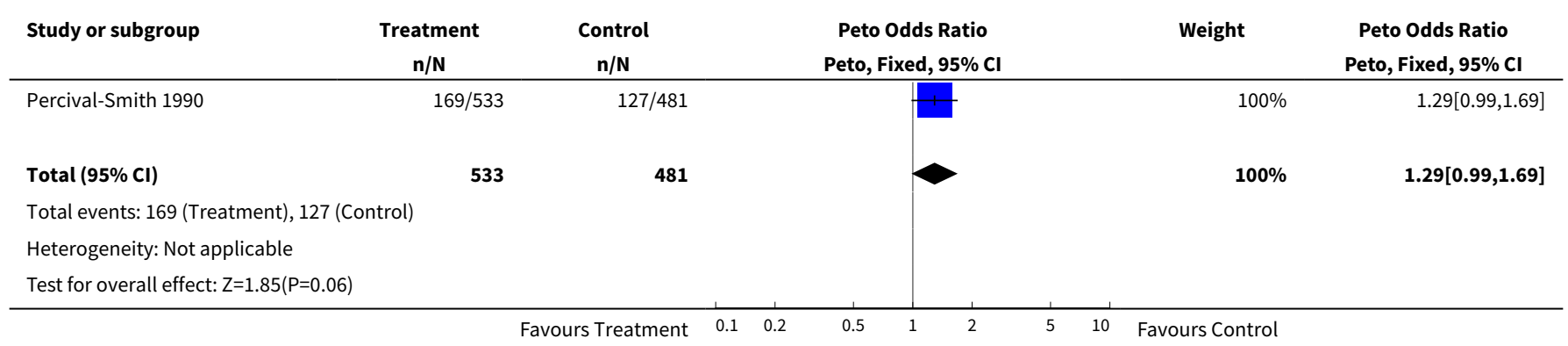

Analysis 1.2. Comparison 1 Biphasic norethindrone/ethinyl estradiol versus monophasic norethindrone acetate/ethinyl estradiol, Outcome 2 Absence of withdrawal bleeding.

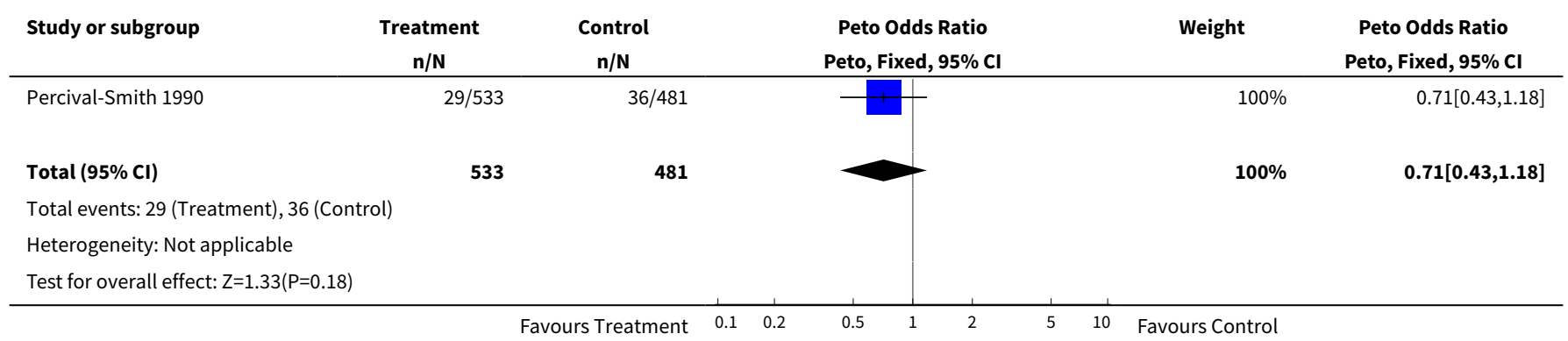

Analysis 1.3. Comparison 1 Biphasic norethindrone/ethinyl estradiol versus monophasic norethindrone acetate/ethinyl estradiol, Outcome 3 Study discontinuation due to intermenstrual bleeding.

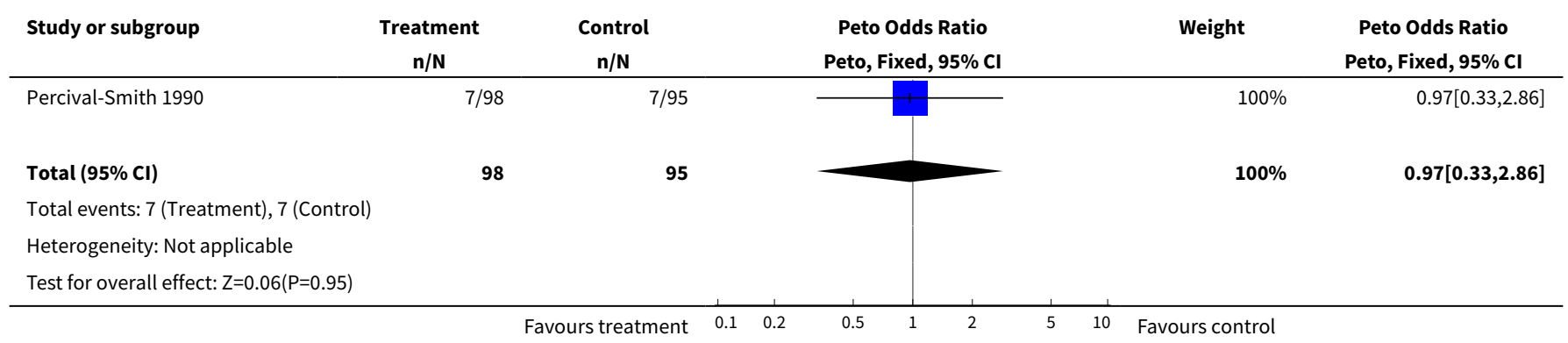




\section{APPENDICES}

\section{Appendix 1. Previous search strategies}

\section{Initial review (2006) and 2008 update}

\section{EMBASE}

1. oral contraceptive agent

2. biphasic

3. triphasic

4. multiphasic

5. 2 OR 3 OR 4

6. 1 AND 5

7. monophasic

8. 6 AND 7

\section{CENTRAL}

1. (contraceptives and oral)

2. monophasic

3. biphasic

4. triphasic

5. multiphasic

6. (((\#2 or \#3) or \#4) or \#5)

7. (\#1 and \#6)

\section{POPLINE}

(kw) oral contraceptives

AND

(tw) (monophasic OR biphasic OR triphasic OR multiphasic)

AND

(tw) (compar* OR clinical trials OR comparative studies OR random OR double blind studies)

\section{ClinicalTrials.gov}

Search terms: biphasic OR triphasic OR multiphasic

Condition: oral contraceptive

\section{ICTRP}

Title: monophasic OR biphasic OR triphasic OR multiphasic Intervention or condition: contraception OR contraceptive

WHAT'S NEW

\begin{tabular}{lll}
\hline Date & Event & Description \\
\hline 4 May 2011 & New search has been performed & Searches updated; no new trials found. \\
\hline
\end{tabular}

\section{H I S T ORY}

Protocol first published: Issue 2, 2000

Review first published: Issue 4, 2001

\begin{tabular}{lll}
\hline Date & Event & Description \\
\hline 25 November 2008 & New search has been performed & $\begin{array}{l}\text { Searches were updated in Oct and Nov 2008; no new trials were } \\
\text { found. Added searches of clinical trials databases. }\end{array}$ \\
\hline
\end{tabular}




\begin{tabular}{lll}
\hline Date & Event & Description \\
\hline 14 April 2008 & Amended & Converted to new review format. \\
\hline 15 May 2006 & $\begin{array}{l}\text { New citation required and conclusions } \\
\text { have changed }\end{array}$ & Substantive amendment \\
\hline
\end{tabular}

\section{CONTRIBUTIONS OF AUTHORS}

F Helmerhorst came up with the idea of comparing multiphasic with monophasic oral contraceptives. For the initial review, D Grimes and $\mathrm{H}$ Van Vliet developed the protocol, conducted the literature searches, assessed the methodological quality of the studies, abstracted the data and entered the data in RevMan. K Schulz verified the correct entry of the data. D Grimes and H Van Vliet wrote the manuscript. $\mathrm{K}$ Schulz and F Helmerhorst advised on, commentated and proof-read the manuscript. For the 2006 update, $\mathrm{H}$ Van Vliet reviewed the search results; L Lopez edited the review for Cochrane style issues, and wrote the Plain Language Summary. For the 2008 and 2011 updates, L Lopez conducted the searches, reviewed the search results, and edited the review.

\section{DECLARATIONS OF INTEREST}

DA Grimes has consulted with the pharmaceutical companies Bayer Healthcare Pharmaceuticals and Merck \& Co, Inc.

\section{SOURCES OF SUPPORT}

\section{Internal sources}

- No sources of support supplied

\section{External sources}

- National Institute of Child Health and Human Development, USA.

- U.S. Agency for International Development, USA.

\section{N DEX TERMS}

\section{Medical Subject Headings (MeSH)}

${ }^{\star}$ Contraception; *Contraceptives, Oral, Synthetic [adverse effects] [chemistry]; ${ }^{\star}$ Estradiol Congeners [adverse effects] [chemistry]; *Ethinyl Estradiol [adverse effects] [chemistry]; *Norethindrone [adverse effects] [chemistry]; Chemistry, Pharmaceutical; Metrorrhagia [chemically induced]; Randomized Controlled Trials as Topic

\section{MeSH check words}

Female; Humans; Pregnancy 